http://asnj.journals.ekb.eg

http://www.arabimpactfactor.com

\title{
Relationship between Fetal Sex and pattern of Nausea, Vomiting and Cholasma among Pregnant women at Assuit city
}

\author{
Walaa H. Ibrahim ${ }^{1}$, Heba M. Mohamed ${ }^{2} \&$ Walaa H. Abdel-fatah ${ }^{3}$. \\ 1.2. Lecturer of Maternal and Neonatal Health Nursing, Faculty of Nursing, Assiut University, Egypt \\ 3. Lecturer of Community Health Nursing, Faculty of Nursing, Assiut University, Egypt.
}

\begin{abstract}
Background: Nausea and vomiting during pregnancy (NVP), is one of the most common complaints of pregnant women. Fetus's gender is one that stimulates these complaints. Aim: This study aimed to assess the relationship between fetal sexand pattern of nausea, vomiting and cholasma among pregnant women. Methods: Descriptive research design. Sample size included 400 pregnant women in their third trimester, that divided into four groups (primi- gravida with female fetus, primi- gravida with male fetus, multi- gravida with female fetus and multi- gravida with male fetus), each group haveone hundred women, The study was conducted at antenatal outpatient clinic, Woman's Health Hospital, Assiut University and Qlta Maternal and Child Health Care center, Assiut, Egypt. Data was collected by using interview questionnaire. Results: This study showed there was relationship between gender of the current pregnancy, pattern, onset, time, frequency, end date of nausea, vomiting and cholasma (p-value 0.001, $0.005,0.001,0.002,0.003$ and 0.003 respectively). Conclusion: This study revealed that NVP and cholasma are more likely to occur among female fetus than male. Recommendations: Increase mother's knowledge about the effect of pregnancy hormones related changes on thier health through health education program.
\end{abstract}

\section{Key Words: Cholasma, Fetal Sex ,Nausea, Pregnancy \& Vomiting.}

\section{Introduction}

Nausea and vomiting of pregnancy (NVP) or called emesis gravidarum are the most common clinical complaints affecting women in the first trimester. It occurs in up to $70 \%$ of pregnant women according to many of studies (Naomi et al., 2019, Pauliinaet al., 2018, Hyun et al., 2018., \& Chortatoset al., 2013). This sickness is generally a mild, self-limited condition that may be controlled with conservative measures (Zare, \& Sekhavat, 2013).

Nausea and vomiting symptoms manifest usually a round 4 and 6 weeks of pregnancy and peak between week 8 and 12. Most of the symptoms disappear by week 20 of gestation (Marie, \& Radka, 2014). Some thesis emphasize that the role of NVP is to safeguard the pregnant women and embryos from pathogens that eat with food and dietary toxins and women who experience NVP have a lower risk of spontaneous abortion and preterm birth than those without such symptoms (Hinkle et al., 2016, Chortatoset al., 2015 \& Korenet al., 2014)

More than 2000 years ago, Hippocrates or Greek medical professions stated that female fetuses give the mother a pale face, whereas a mother carrying a male fetus has a healthier tone to her skin. Some studies notified that pregnant women during first trimester exposed to hyperemesis gravidarum give birth to a higher rate of female newborns than do all mothers (Naomi et al., 2019, Nayak, \& Sunanda, 2017, Zare \& Sekhavat, 2013 \& Christopher et al.,
2012) This related to that the circulating levels of the placental glycoprotein hormone, human chorionic gonadotropin (hCG) are higher in women carrying female versus male fetuses according to some studies (Adibi et al., 2015, Lorzadeh, \& Kazemirad., 2013). Cholasma or melasma is a common skin change influenced by pregnancy hormones as estrogen and progesterone which lead to brownish skin tone (National Institutes of Health, 2016). Before the presence of ultrasound, people came up with all kind of ways to tell whether a pregnant woman carried a boy or girl, one of these methods even involved looking at the skin pigmentation changes often associated with pregnancy (Sarkar \& Bansal., 2017).NVP can have a significant impact on family life, on the ability to perform usual daily activities, on social functioning and on stress levels. In addition, the presence and severity of NVP have been shown to have an impact on the quality of life (QOL) of pregnant women so community health nurse play important role to educate mother and increase their awareness related to these health issue.

\section{Significant of the study}

There is little recent information on the relation between fetus's genders with NVP. According to previous studies, it has been suggested that elevated human chorionic gonadotropin (HCG) is associated with NVP. Women carrying female fetuses have higher HCG levels than women carrying male fetuses(Veenendaal et al., 2011). 
As a result of traditional believes of women in Egyptian society, especially in Upper Egypt, Saying that woman have female fetus more complain of nausea and vomiting and darkness of skin coloration (cholasma) or less beauty than woman have male fetus. So based on scientific method utilize this study to assessed the relation between fetal sex ,NVP and cholasma.

\section{Aim of the study}

\section{The present study aimed to}

- Assess relationship between fetal sex and pattern of nausea, vomiting and cholasma during pregnancy among primi and multi gravida.

\section{Research Questions}

- Is there a relationship between fetal sex and pattern of NVP and cholasma?

- Is pattern of NVP and cholasma differing between primi and multi gravida?

\section{Patient \& Methods \\ Research design: Descriptive research design.}

Study setting: The study was conducted at antenatal outpatient clinic, Woman's Health Hospital (a tertiary referral center and one of the largest teaching hospitals in Upper Egypt),Assiut University, Egypt and Qlta Maternal and Child health Care center. Both of them serves all women from rural and urban areas.

\section{Study subjects}

The current study recruited 400 pregnant women in their third trimester, classified to one hundred primigravida women with female fetus, one hundred primigravida women with male fetus, one hundred multigravida women with female fetus and one hundred multi-gravida women with male fetus attending to the antenatal outpatient clinic and Qlta Maternal and Child health Care center for antenatal care.

\section{Sample size calculation}

It was calculated by Open Epi-Info Statistical Package, Version 7.2.0.1 using the sample size equation for estimation of single proportion. The total numbers of pregnant women who were studied in the selected courses during data collection were 378 pregnant women. It was raised to include 400 pregnant women to compensate the previous classification of cases or refusals. With precision levels $5 \%$ where confidence level is $95 \%$ and $\mathrm{p}<$ 0.05 .

\section{Inclusion criteria}

women in child-bearing period with normal and singleton pregnanciesin their third trimester of pregnancy and accepted to take part in the study.

\section{Exclusion criteria}

women who had known maternal disease affect pattern of nausea, vomiting and cholasma during pregnancy as (upper gestational tract disease vestibular disease, liver disease, or hyperthyroidism).

Tool of the study

Structured interview questionnaire

Data was collected by using interview questionnaire that was designed by researcher included two parts, part one involved personal data, and obstetric data as age, address for resident, level of education, occupation, obstetric history and current obstetric data.Part two involved data about pattern of nausea and vomiting asonset of symptoms, time of vomiting through the day, frequency of vomiting, end date of vomiting.....etc and observe for women's face for cholasma by the researcher.

\section{Reliability of a tool}

The internal consistency of the tool scale was calculated by using Cronbach's Alpha; and it was 0.836 .

Validity of questionnaire

Questionnaire was examined and reappraised by a group of specialists in the field of Obstetrics \&Gynecological nursing and community health nursing and was assessed in a pilot study. The panel reviewed the instruments for clarity, relevance, comprehensiveness, understanding and applicability.

\section{Operational design}

This included the pilot study and data collection phase.

\section{Pilot study}

A pilot study was conducted on a sample of $10 \%$ of women (40) attending to antenatal clinic, Woman's Health Hospital, Assiut University and Qlta Maternal and Child health Care centers to test the applicability of the tools and test the clarity of the designated questionnaire as well as to estimate the time needed to answer it. It also helped to test the feasibility and suitability of the study settings. Data obtained from the pilot were analyzed and included from the number of study sample because no essential modifications were done.

\section{Administration design}

To carry out the study; the necessary approval was obtained from the director of Woman's Health Hospital and the director of Qlta Maternal and Child HealthCare Center. The researchers explained the aims of the study and requesting permission to use the premise for data collection.

\section{Ethical consideration}

The study proposal took agreement from the ethical committee of the faculty of nursing, Assiut University. An official permission to carry out the study was obtained from the responsible authorities. Informed consent was obtained from the study participants after explaining the purpose and nature of the study. Also, assure them that their participation would not be used against them in any way and they 
have the right to refuse or to decide to terminate their participation at any time.

\section{Data collection phase}

Data were collected from the participant women through interviewed the women attending to outpatient clinics, Qlta Maternal and Child health Care Center individually after explanation the nature of the study and obtained their consent to be included in the study. The researcher informed the participant that their participation is voluntary. Confidentiality and anonymity of subjects were assured by the researcher.

The researchers met all pregnant women in third trimester attending to outpatient clinicsof Women Health Hospital through three days in a week from 8 am to $12,30 \mathrm{pm}$, great women, introduce self and explain purpose and important of the study. The data collection took about 20 minutes for each participant from February to May 2019 participants classified to fifty primi-gravida women with female fetus, fifty primi-gravida women with male fetus, fifty multigravida women with female fetus and fifty multigravida women with male fetus.on the other hand the same number of participant from Qlta Maternal \& Child health Care Center data and the collected through three days in a week from 8 am to $12,30 \mathrm{pm}$ from June to October 2019.The whole duration of data collection took about nine months, started from February to October 2019.

\section{Statistical design}

Data entry and analysis were done using SPSS version 18 Program statistical software package for social sciences. Data were presented using descriptive statistics in the form of frequencies and percentages. Also, Mean was calculated. Correlation between variables (Pearson correlation) and (t-test) were used statistical significance was considered at P-value $\leq 0.05$.

\section{Results}

Table (1): Distribution of pregnant women according to their personal data $(n=400)$.

\begin{tabular}{|c|c|c|c|c|c|c|c|c|c|c|c|}
\hline \multirow{2}{*}{ Personal data } & \multicolumn{2}{|c|}{$\begin{array}{c}\text { Primigravida } \\
\text { male }\end{array}$} & \multicolumn{2}{|c|}{$\begin{array}{l}\text { Primigravida } \\
\text { female }\end{array}$} & \multirow[t]{2}{*}{$\begin{array}{c}\text { p- } \\
\text { value }\end{array}$} & \multicolumn{2}{|c|}{$\begin{array}{c}\text { Multigravida } \\
\text { male }\end{array}$} & \multicolumn{2}{|c|}{$\begin{array}{c}\text { Multigravida } \\
\text { female }\end{array}$} & \multirow[t]{2}{*}{$\begin{array}{c}\text { P- } \\
\text { value }\end{array}$} & \multirow{2}{*}{ Total } \\
\hline & No & $\%$ & No & $\%$ & & No & $\%$ & No & $\%$ & & \\
\hline \multicolumn{10}{|l|}{ 1)Age: (years) } & \multirow{5}{*}{0.882} & \multirow{5}{*}{400} \\
\hline - Less than 20 years & 22 & 5.5 & 24 & 6.0 & \multirow{4}{*}{0.579} & 2 & 0.5 & 3 & 0.75 & & \\
\hline - $20-<35$ year & 77 & 19.25 & 76 & 19.0 & & 78 & 19.5 & 76 & 19.0 & & \\
\hline More than 35 years & 1 & 0.25 & 0 & 0.0 & & 20 & 5.0 & 21 & 5.25 & & \\
\hline Total & 100 & 25.0 & 100 & 25.0 & & 100 & 25.0 & 100 & 25.0 & & \\
\hline \multicolumn{5}{|l|}{ 2)Occupation: } & \multirow{4}{*}{0.421} & & & & & \multirow{4}{*}{0.602} & \multirow{4}{*}{400} \\
\hline - Employed & 6 & 1.5 & 9 & 2.25 & & 7 & 1.75 & 9 & 2.25 & & \\
\hline - Not employed & 94 & 23.5 & 91 & 22.75 & & 93 & 23.25 & 91 & 22.75 & & \\
\hline Total & 100 & 25.0 & 100 & 25.0 & & 100 & 25.0 & 100 & 25.0 & & \\
\hline \multicolumn{5}{|l|}{ 3)Residence: } & \multirow{4}{*}{0.519} & & & & & \multirow{4}{*}{0.648} & \multirow{4}{*}{400} \\
\hline • Urban & 24 & 6.0 & 28 & 7.0 & & 33 & 8.25 & 30 & 7.5 & & \\
\hline - $\quad$ Rural area & 76 & 19.0 & 72 & 18.0 & & 67 & 16.75 & 70 & 17.5 & & \\
\hline Total & 100 & 25.0 & 100 & 25.0 & & 100 & $25 \%$ & 100 & $25 \%$ & & \\
\hline \multicolumn{5}{|l|}{ 4)Education: } & \multirow{6}{*}{0.113} & & & & & \multirow{6}{*}{0.817} & \multirow{6}{*}{400} \\
\hline - No education & 17 & 4.25 & 6 & 1.5 & & 23 & 5.75 & 22 & 5.5 & & \\
\hline Basic education & 35 & 8.75 & 39 & 9.75 & & 24 & 6.0 & 30 & 7.5 & & \\
\hline $\begin{array}{l}\text { Secondary } \\
\text { education }\end{array}$ & 33 & 8.25 & 37 & 9.25 & & 43 & 10.75 & 39 & 9.75 & & \\
\hline - $\quad$ University & 15 & 3.75 & 18 & 4.5 & & 10 & 2.5 & 9 & 2.25 & & \\
\hline Total & 100 & 25.0 & 100 & 25.0 & & 100 & 25.0 & 100 & 25.0 & & \\
\hline
\end{tabular}


Table (2): Distribution of pregnant women according to current nausea and vomiting data (n=400).

\begin{tabular}{|c|c|c|c|c|c|c|c|c|c|c|c|}
\hline \multirow{2}{*}{$\begin{array}{l}\text { Current nausea and } \\
\text { vomiting data }\end{array}$} & \multicolumn{2}{|c|}{$\begin{array}{c}\text { Primigravida } \\
\text { male }\end{array}$} & \multicolumn{2}{|c|}{$\begin{array}{c}\text { Primigravida } \\
\text { female }\end{array}$} & \multirow[t]{2}{*}{$\begin{array}{c}\text { p- } \\
\text { value }\end{array}$} & \multicolumn{2}{|c|}{$\begin{array}{c}\text { Multigravida } \\
\text { male }\end{array}$} & \multicolumn{2}{|c|}{$\begin{array}{c}\text { Multigravida } \\
\text { female }\end{array}$} & \multirow[t]{2}{*}{$\begin{array}{c}\mathrm{P}- \\
\text { value }\end{array}$} & \multirow[t]{2}{*}{ otal } \\
\hline & No & $\%$ & No & $\%$ & & No & $\%$ & No & $\%$ & & \\
\hline \multicolumn{5}{|c|}{ 1)Pattern of nausea and vomiting } & \multirow{6}{*}{.052} & & & & & \multirow{6}{*}{$.001 * *$} & \multirow{6}{*}{400} \\
\hline - No symptoms & 14 & 3.5 & 11 & 2.75 & & 31 & 7.75 & 10 & 2.5 & & \\
\hline - Nausea only & 19 & 4.75 & 10 & 2.5 & & 19 & 4.75 & 23 & 5.75 & & \\
\hline $\begin{array}{l}\text { - Nausea and } \\
\text { vomiting }\end{array}$ & 61 & 15.25 & 63 & 15.75 & & 44 & 11.0 & 51 & 12.75 & & \\
\hline $\begin{array}{l}\text { - Hyperemesis } \\
\text { graviderium }\end{array}$ & 6 & 1.5 & 16 & 4.0 & & 6 & 1.5 & 16 & 4.0 & & \\
\hline Total & 100 & 25.0 & 100 & 25.0 & & 100 & 25.0 & 100 & 25.0 & & \\
\hline \multicolumn{5}{|c|}{ 2) Onset of symptoms at week } & \multirow{5}{*}{.367} & & & & & \multirow{5}{*}{$.001 * *$} & \multirow{5}{*}{400} \\
\hline - No symptoms & 14 & 3.5 & 11 & 2.75 & & 31 & 7.75 & 10 & 2.5 & & \\
\hline - Before 6 week & 60 & 15.0 & 54 & 13.5 & & 43 & 10.75 & 62 & 15.5 & & \\
\hline - After 6 week & 26 & 6.5 & 35 & 8.75 & & 26 & 6.5 & 28 & 7.0 & & \\
\hline Total & 100 & 25.0 & 100 & 25.0 & & 100 & 25.0 & 100 & 25.0 & & \\
\hline \multicolumn{5}{|l|}{ 3)Time of vomiting } & \multirow{5}{*}{.430} & & & & & \multirow{5}{*}{$.003 * *$} & \multirow{5}{*}{400} \\
\hline - No symptoms & 14 & 3.5 & 11 & 2.75 & & 31 & 22.75 & 10 & 2.5 & & \\
\hline - At morning & 33 & 8.25 & 27 & 6.75 & & 33 & 8.25 & 34 & 8.5 & & \\
\hline - Around the day & 53 & 13.25 & 62 & 15.5 & & 36 & 9.0 & 56 & 14.0 & & \\
\hline Total & 100 & 25.0 & 100 & 25.0 & & 100 & 25.0 & 100 & 25.0 & & \\
\hline \multicolumn{5}{|c|}{ 4)Frequency of vomiting } & \multirow{6}{*}{.126} & & & & & \multirow{6}{*}{$.004 * *$} & \multirow{6}{*}{400} \\
\hline - No symptoms & 14 & 3.5 & 11 & 2.75 & & 31 & 7.75 & 10 & 2.5 & & \\
\hline - Nausea only & 18 & 4.5 & 13 & 3.25 & & 21 & 5.25 & 20 & 5.0 & & \\
\hline - Once & 29 & 7.25 & 21 & 5.25 & & 20 & 5.0 & 14 & 3.5 & & \\
\hline - More than one & 39 & 9.75 & 55 & 13.75 & & 28 & 7.0 & 56 & 14.0 & & \\
\hline Total & 100 & 25.0 & 100 & 25.0 & & 100 & 25.0 & 100 & 25.0 & & \\
\hline \multicolumn{5}{|c|}{ 5)End date of vomiting } & \multirow{5}{*}{.778} & & & & & \multirow{5}{*}{$.002 * *$} & \multirow{5}{*}{400} \\
\hline - No symptoms & 14 & 3.5 & 11 & 2.75 & & 31 & 7.75 & 10 & 2.5 & & \\
\hline $\begin{array}{l}\text { - Before or equal } \\
12 \text { week }\end{array}$ & 30 & 7.5 & 33 & 8.25 & & 34 & 8.5 & 30 & 7.5 & & \\
\hline - After 12 week & 56 & 14.0 & 56 & 14.0 & & 35 & 8.75 & 60 & 15.0 & & \\
\hline Total & 100 & 25.0 & 100 & 25.0 & & 100 & 25.0 & 100 & 25.0 & & \\
\hline
\end{tabular}

(**) highly statistically significant $p<0.01$

Table (3): Relationship between pregnant women's age and current nausea and vomiting data (n=400).

\begin{tabular}{|c|c|c|c|c|c|c|c|c|}
\hline \multirow{3}{*}{$\begin{array}{c}\text { Current nausea and vomiting } \\
\text { data }\end{array}$} & \multicolumn{6}{|c|}{ Age group } & \multirow{3}{*}{ Total } & \multirow{3}{*}{ P-value } \\
\hline & \multicolumn{2}{|c|}{ less than 20 year } & \multicolumn{2}{|c|}{$20<35$ year } & \multicolumn{2}{|c|}{ more than 35 year } & & \\
\hline & No & $\%$ & No & $\%$ & No & $\%$ & & \\
\hline \multicolumn{7}{|c|}{ 1)Pattern of nausea and vomiting } & \multirow{6}{*}{400} & \multirow{6}{*}{.240} \\
\hline - No symptoms & 8 & 2.0 & 45 & 11.25 & 13 & 3.25 & & \\
\hline - Nausea only & 10 & 2.5 & 54 & 13.5 & 7 & 1.75 & & \\
\hline - Nausea and vomiting & 28 & 7.0 & 174 & 43.5 & 17 & 4.25 & & \\
\hline - Hyperemesis graviderium & 5 & 1.25 & 34 & 8.5 & 5 & 1.25 & & \\
\hline Total & 51 & 12.75 & 307 & 76.75 & 42 & 10.5 & & \\
\hline \multicolumn{7}{|l|}{ 2)Onset of symptoms at week } & \multirow{5}{*}{400} & \multirow{5}{*}{$.027 *$} \\
\hline - No symptoms & 8 & 2.0 & 45 & 11.25 & 13 & 3.25 & & \\
\hline - Before 6 week & 24 & 6.0 & 172 & 43 & 23 & 5.75 & & \\
\hline - After 6 week & 19 & 4.75 & 90 & 22.5 & 6 & 1.5 & & \\
\hline Total & 51 & 12.75 & 307 & 76.75 & 42 & 10.5 & & \\
\hline \multicolumn{7}{|l|}{ 3)Time of vomiting } & \multirow{5}{*}{400} & \multirow{5}{*}{.060} \\
\hline - No symptoms & 8 & 2.0 & 45 & 11.25 & 13 & 3.25 & & \\
\hline - At morning & 14 & 3.5 & 102 & 25.5 & 14 & 3.5 & & \\
\hline - Around the day & 29 & 7.25 & 160 & 40.0 & 15 & 3.75 & & \\
\hline Total & 51 & 12.75 & 307 & 76.75 & 42 & 10.5 & & \\
\hline
\end{tabular}


Ibrahim et al.,

\begin{tabular}{|c|c|c|c|c|c|c|c|c|}
\hline \multirow{3}{*}{$\begin{array}{c}\text { Current nausea and vomiting } \\
\text { data }\end{array}$} & \multicolumn{6}{|c|}{ Age group } & \multirow{3}{*}{ Total } & \multirow{3}{*}{ P-value } \\
\hline & \multicolumn{2}{|c|}{ less than 20 year } & \multicolumn{2}{|c|}{$20<35$ year } & \multicolumn{2}{|c|}{ more than 35 year } & & \\
\hline & No & $\%$ & No & $\%$ & No & $\%$ & & \\
\hline \multicolumn{7}{|l|}{ 4)Frequency of vomiting } & \multirow{6}{*}{400} & \multirow{6}{*}{.193} \\
\hline - No symptoms & 8 & 2.0 & 45 & 11.25 & 13 & 3.25 & & \\
\hline - Nausea only & 11 & 2.75 & 53 & 13.25 & 7 & 1.75 & & \\
\hline - Once & 8 & 2.0 & 68 & 17.0 & 9 & 2.25 & & \\
\hline - More than one & 24 & 6.0 & 141 & 35.25 & 13 & 3.25 & & \\
\hline Total & 51 & 12.75 & 307 & 76.75 & 42 & 10.5 & & \\
\hline \multicolumn{7}{|l|}{ 5)End date of vomiting } & \multirow{5}{*}{400} & \multirow{5}{*}{.101} \\
\hline - No symptoms & 8 & 2.0 & 45 & 11.25 & 13 & 3.25 & & \\
\hline - before or equal 12 week & 16 & 4.0 & 102 & 25.5 & 9 & 2.25 & & \\
\hline - after 12 week & 27 & 6.75 & 160 & 40.0 & 20 & 5.0 & & \\
\hline Total & 51 & 12.75 & 307 & 76.75 & 42 & 10.5 & & \\
\hline
\end{tabular}

(*) statistically significant $p<0.05$

Table (4): Relationship between current gender of baby and nausea and vomiting data ( $n=400)$.

\begin{tabular}{|c|c|c|c|c|c|c|}
\hline \multirow{3}{*}{ Current nausea and vomiting data } & \multicolumn{4}{|c|}{ Gender of baby of current pregnancy } & \multirow[t]{3}{*}{ Total } & \multirow[t]{3}{*}{ p-value } \\
\hline & \multicolumn{2}{|c|}{ Male } & \multicolumn{2}{|c|}{ Female } & & \\
\hline & No & $\%$ & No & $\%$ & & \\
\hline \multicolumn{5}{|l|}{ 1)Pattern of nausea and vomiting } & \multirow{6}{*}{400} & \multirow{6}{*}{$.001 * *$} \\
\hline - No symptoms & 45 & 11.25 & 21 & 5.25 & & \\
\hline$\bullet$ Nausea only & 38 & 9.5 & 33 & 8.25 & & \\
\hline - Nausea and vomiting & 105 & 26.25 & 114 & 28.5 & & \\
\hline -Hyperemesis graviderium & 12 & 3.0 & 32 & 8.0 & & \\
\hline Total & 200 & 50.0 & 200 & $\mathbf{5 0 . 0}$ & & \\
\hline \multicolumn{5}{|l|}{ 2)Onset of symptoms at week } & \multirow{5}{*}{400} & \multirow{5}{*}{$.005 * *$} \\
\hline - No symptoms & 45 & 11.25 & 21 & 5.25 & & \\
\hline - Before 6 week & 103 & 25.75 & 116 & 29.0 & & \\
\hline - After 6 week & 52 & 13.0 & 63 & 15.75 & & \\
\hline Total & 200 & 50.0 & 200 & 50.0 & & \\
\hline \multicolumn{5}{|l|}{ 3)Time of vomiting } & \multirow{5}{*}{400} & \multirow{5}{*}{$.001 * *$} \\
\hline - No symptoms & 45 & 11.25 & 21 & 5.25 & & \\
\hline - At morning & 96 & 24.0 & 61 & 15.25 & & \\
\hline - Around the day & 86 & 21.5 & 118 & 29.5 & & \\
\hline Total & 200 & 50.0 & 200 & 50.0 & & \\
\hline \multicolumn{5}{|l|}{ 4)Frequency of vomiting } & \multirow{6}{*}{400} & \multirow{6}{*}{$.002 * *$} \\
\hline - No symptoms & 45 & 11.25 & 21 & 5.25 & & \\
\hline - Nausea only & 39 & 9.75 & 32 & 8.0 & & \\
\hline - Once & 49 & 12.25 & 36 & 9.0 & & \\
\hline - More than one & 67 & 16.75 & 111 & 27.75 & & \\
\hline Total & 200 & 50.0 & 200 & 50.0 & & \\
\hline \multicolumn{5}{|l|}{ 5)End date of vomiting } & \multirow{5}{*}{400} & \multirow{5}{*}{$.003 * *$} \\
\hline - No symptoms & 45 & 11.25 & 21 & 5.25 & & \\
\hline - before or equal 12 week & 64 & 16.0 & 63 & 15.75 & & \\
\hline - after 12 week & 91 & 22.75 & 116 & 29.0 & & \\
\hline Total & 200 & 50.0 & 200 & 50.0 & & \\
\hline
\end{tabular}

(**) highly statistically significant $p<0.01$ 
Table (5): Relationship between parity and current nausea and vomiting data $(n=400)$.

\begin{tabular}{|c|c|c|c|c|c|c|c|c|}
\hline \multirow{3}{*}{ Current nausea and vomiting data } & \multicolumn{6}{|c|}{ Parity } & \multirow{3}{*}{ Total } & \multirow{3}{*}{ P-value } \\
\hline & \multicolumn{2}{|c|}{ Non } & \multicolumn{2}{|c|}{ Pirmipara } & \multicolumn{2}{|c|}{ Multipara } & & \\
\hline & No & $\%$ & No & $\%$ & No & $\%$ & & \\
\hline \multicolumn{7}{|l|}{ 1)Pattern of nausea and vomiting } & \multirow{6}{*}{400} & \multirow{6}{*}{$.046 *$} \\
\hline • No symptoms & 25 & 6.25 & 5 & 1.25 & 36 & 9.0 & & \\
\hline - Nausea only & 29 & 7.25 & 9 & 2.25 & 33 & 8.25 & & \\
\hline - Nausea and vomiting & 124 & 31.0 & 18 & 4.5 & 77 & 19.25 & & \\
\hline •Hyperemesis graviderium & 22 & 5.5 & 6 & 1.5 & 16 & 4.0 & & \\
\hline Total & 200 & 50.0 & 38 & 9.5 & 162 & 40.5 & & \\
\hline \multicolumn{7}{|l|}{ 2)Onset of symptoms at week } & \multirow{5}{*}{400} & \multirow{5}{*}{.098} \\
\hline - No symptoms & 25 & 6.25 & 5 & 1.25 & 36 & 9.0 & & \\
\hline - Before 6 week & 114 & 28.5 & 19 & 4.75 & 86 & 21.5 & & \\
\hline - After 6 week & 61 & 15.25 & 14 & 3.5 & 40 & 10.0 & & \\
\hline Total & 200 & 50.0 & 38 & 9.5 & 162 & 40.5 & & \\
\hline \multicolumn{7}{|l|}{ 3)Time of vomiting } & \multirow{5}{*}{400} & \multirow{5}{*}{$.050 *$} \\
\hline - No symptoms & 25 & 6.25 & 5 & 1.25 & 36 & 9.0 & & \\
\hline - At morning & 60 & 15.0 & 15 & 3.75 & 55 & 13.75 & & \\
\hline - Around the day & 115 & 28.75 & 18 & 4.5 & 71 & 17.75 & & \\
\hline Total & 200 & 50.0 & 38 & 9.5 & 162 & 40.5 & & \\
\hline \multicolumn{7}{|l|}{ 4)Frequency of vomiting } & \multirow{6}{*}{400} & \multirow{6}{*}{.100} \\
\hline - No symptoms & 25 & 6.25 & 5 & 1.25 & 36 & 9.0 & & \\
\hline - Nausea only & 30 & 7.5 & 9 & 2.25 & 32 & 8.0 & & \\
\hline - Once & 51 & 12.75 & 6 & 1.5 & 28 & 7.0 & & \\
\hline - More than one & 94 & 23.5 & 18 & 4.5 & 66 & 16.5 & & \\
\hline Total & 200 & 50.0 & 38 & 9.5 & 162 & 40.5 & & \\
\hline \multicolumn{7}{|l|}{ 5)End date of vomiting } & \multirow{5}{*}{400} & \multirow{5}{*}{.106} \\
\hline - No symptoms & 25 & 6.25 & 5 & 1.25 & 36 & 9.0 & & \\
\hline - before or equal 12 week & 63 & 15.75 & 15 & 3.75 & 49 & 12.25 & & \\
\hline - after 12 week & 112 & 28.0 & 18 & 4.5 & 77 & 19.25 & & \\
\hline Total & 200 & $\mathbf{5 0 . 0}$ & 38 & 9.5 & 162 & 40.5 & & \\
\hline
\end{tabular}

(*) statistically significant $p<0.05$.

\section{Relationship between gender of baby of current pregnancy and facial changes of pregnant women}

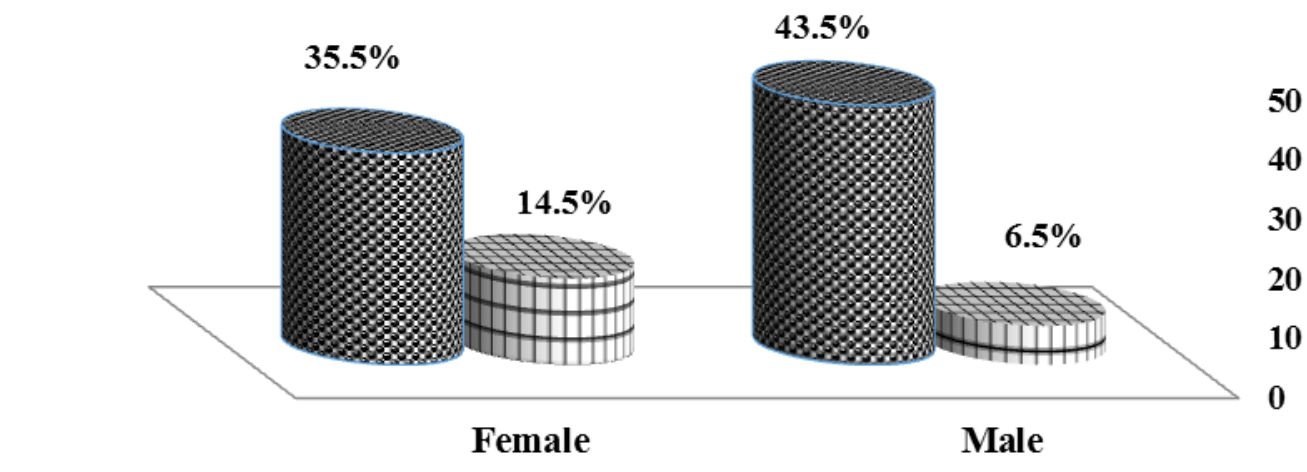

P-value 0.003

HPresent Not present

Figure (1): Relationship between gender of baby of current pregnancy and facial changes (cholasma) of pregnant $\operatorname{women}(n=400)$. 
Table (1): Illustrates that the greater percent of pregnant women were found in age group ( $20<35$ years old) with total percent of $76.75 \%$. The great majority $(92.25 \%)$ of them were not employed, more than two thirds $(71.25 \%)$, of them were lived in rural areas and more than one third (38\%) had secondary school with no significant difference between male and female in primi and multigravida women.

Table (2): States that no significant difference between male and female fetus primigravida women regarding pattern, onset, time, frequency, and end date of nausea and vomiting (p-value 0.052, 0.367, $0.430,0.126$ and 0.778 respectively). On the other hand there are significant difference between male and female fetus multigravida women regarding the same variables and the same sequence (p-value $0.001,0.001,0.003,0.004$ and 0.002 respectively).

Table (3): Clears that there is no relationship between age group and pattern, time, frequency, and end date of nausea and vomiting ( $\mathrm{p}$-value 0.240 , 0.060 , and 0.193 respectively). But it also shows that there are relationship between age group and onset of nausea and vomiting (p-value 0.027).

Table (4) Reports that there is relationship between gender of the current pregnancy and pattern, onset, time, frequency, and end date of nausea and vomiting (p-value $0.001, \quad 0.005, \quad 0.001, \quad 0.002, \quad 0.003$ respectively).

Table (5): Confirms that there is no relationship between parity and pattern, onset, time, frequency, and end date of nausea and vomiting (p-value 0.046, $0.098,0.050,0.100,0.106$ respectively).

Figure (1): Shows that there is relationship between gender of baby of current pregnancy and facial changes of pregnant women ( $p$-value 0.003).

\section{Discussion}

The most common complaints affecting pregnant women in the first trimester is NVP. Its cause remains unknown and factors associated with the occurrence of NVP are different (Marie \& Radka, 2014). So, this study aim to assess the relationship between fetal sex and pattern of nausea \& vomiting and cholasma during pregnancy.

Morning sickness or NVP is common problem during pregnancy (Einarson et al, 2013). Symptoms and pattern of it range from mild nausea to hyperemesis gravidarum. Experiences of NVP vary greatly, but it typically starts between $4^{\text {th }}-6^{\text {th }}$ weeks of gestation, peaks between $8^{\text {th }}$ and $12^{\text {th }}$ weeks, and then disappears by $20^{\text {th }}$ weeks of gestation (Sarah et al., 2017).

Concerning NVP in the present study there was no significant difference between male and female fetuses among primi-gravida women regarding pattern, onset, time, frequency, and end date of nausea and vomiting (p-value 0.052, 0.367, 0.430, 0.126 and 0.778 respectively) with worsening in frequency of nausea and vomiting in more than half female fetus than nearly two thirds male fetus. On the other hand there was significant difference between male and female multigravida women regarding the same variables and the same sequence ( $\mathrm{p}$-value $0.001,0.001,0.003,0.004$ and 0.002 respectively).

This is similar to Vida \& Zakeri(2017), who applied their study in Tonekabon to determine relation between nausea and vomiting in pregnancy and fetal gender, they revealed that there was significant relation morning sickness and fetal gender ( $\mathrm{P}$-value 0.001 ), also frequency of nausea \&vomiting were more in females fetus $55.40 \%$ versus $36.18 \%$ in male. On the same line Chortatos et al., (2015), who performed their study on Norwegian mothers to compare pregnancy complications and birth outcomes for women experiencing nausea and vomiting in pregnancy, or nausea only, with symptom-free women, and found that, there was relation between fetal gender and nausea and vomiting in pregnancy (P-value 0.001) as well as Zare \& Sekhavat,( 2013)who implemented their study in Iran to identify relationship between fetal sex and NVP and showed that there was relation between fetal gender and nausea and vomiting in pregnancy (P-value 0.03).

Also Naomi. et al(2019), who conducted their study in Japan to compare morning sickness in singleton and twin pregnancies and its relation to fetal sex, they cleared that there was relation between NVP and fetal sex for singleton and twin pregnancies $\mathrm{P}$-value for both $<0.001$.

During pregnancy some women have a dark irregular patch on their face and forehead that called 'chloasma' or pregnancy mask. Chloasma most commonly to occur when pregnant women exposed to sun (Pregnancy, Birth \& Baby, 2019).

When looking to relationship between fetal sex of current pregnancy and facial changes (chloasma), it is obvious that there is relationship between fetal sex and chloasma(P-value 0.003). On the same line pregnancy, Birth \& Baby 2019 reported that chloasma occurs due to stimulation of pigmentproducing cells by female sex hormones.

As regard relationship between maternal age and NVP, the current study released that there is no relation between age and nausea and vomiting pattern, time, frequency, and end date ( $\mathrm{p}$-value 0.240 , $0.060,0.193$, and 0.101 respectively).

These findings are on the same line Pauliina et al., (2018), who performed their study in Turku to evaluate the severity of NVP with a structured questionnaire and evaluate associative risk factors, 
and revealed that there was no relation between maternal age and NVP (p-value 0.370). Also Zare $\boldsymbol{\&}$ Sekhavat, (2013) \& Hyun et al., (2018), who implemented their study on Koreaon pregnant women to assess association between severity of NVP and pregnancy outcomes and poorer quality of life (QOL), had the same opinion with (p-value 0.3 and 0.160 respectively).

Regarding parity and its relation to NVP, the present study confirms that there is no relationship between parity and pattern, onset, time, frequency, and end date of nausea and vomiting ( $\mathrm{p}$-value 0.046, 0.098, $0.050,0.100,0.106$ respectively).

On the other side Marie \& Radka (2014), who performed their study to describe the quality of life (QOL) of women who developed NVP and to identify whether pregnant women's QOL is influenced by the severity of NVP, parity, duration of pregnancy, gynecologic history, age or marital status. They found that there was relation between parity and NVP (p-value 0.001).

The current study revealed that more than three quarters of all groups (primi with male fetus, primi with female fetus, multi with male fetus, and multi with female fetus) have an age group (20<35years old). The great majority of them were not employed ,the nearly three quarters of them were lived in rural areas, more than one third had secondary school education with no significant difference between male and female in primi and multi gravida women.

Ahwinahwi et al., (2016), who applied their study in Nigeria evaluated the health regarding quality of life of women with nausea and vomiting for pregnancy and found that there were similarity between current study and their study in the level of education as secondary education estimated $34.5 \%$, also age group between 21-32 years were $69.7 \%$, but $46.2 \%$ of studied women were not employed.

On the other hand, Hyun et al., (2018) reported that more than half $(59.1 \%)$ of studied women have age more than 35 years old and employed. The great majority $91.1 \%$ of them have a university level of education. This difference explains difference in location and culture between two places.

According to history of abortion current study reports that the majority of studied women had no abortion, this is in accordance with Mojgan \& Minoor (2015)who showed that $81.3 \%$ of pregnant women had no abortion. But, Chortatos et al., (2015)showed that $28.4 \%$ of pregnant women had previous still birth or spontaneous abortion.

\section{Conclusion}

This study revealed that NVP and cholasma are more likely to occur in female fetus than male.

\section{Recommendation}

Increase mothers' knowledge about the effect of pregnancy hormones related changes on their health through health education program.

\section{Acknowledgment}

We would like to express our appreciation to all pregnant women included in the study and to all individuals involved in the data collection.

\section{References}

1. Ahwinahwi Ufuoma Shalom, Odili Valentine Uche \& Elumelu Sabina, (2016): Healthrelated quality of life of women with nausea and vomiting in pregnancy attending a maternal clinic in Nigeria, IOSR Journal Of Pharmacy www.iosrphr.org (e)-ISSN: 2250-3013, (p)ISSN: 2319-4219 Volume 6, Issue 7 Version, PP. 01-06.

2. Adibi J., Lee M., Saha S., Boscardin W., Apfel, A \& Currier R., (2015): Fetal sex differences in human chorionic gonadotropin fluctuate by maternal race, age, weight and by gestational age, J DevOrig Health Dis, Dec; 6 (6): 493-500.

3. Chortatos A., Margaretha Haugen, Per Ole Iversen, Åse Vikanes, Malin Eberhard-Gran, Elisabeth Krefting Bjelland, Per Magnus and Marit B., Veierød., (2015):Pregnancy complications and birth outcomes among women experiencing nausea only or nausea and vomiting during pregnancy in the Norwegian Mother and Child Cohort Study, BMC Pregnancy and Childbirth 15:138 Page 2 of 11 .

4. Chortatos. A., Haugen. M., Iversen. P., Vikanes. A., Magnus., P., \& Veierød M., (2013): Nausea and vomiting in pregnancy: associations with maternal gestational diet and lifestyle factors in the Norwegian Mother and Child Cohort Study, University of Oslo, Norway, BJOG: 120:1642-1653.

5. Christopher, R., Naumann. C., Zelig, C., Peter G., \& Cynthia W., (2012): Nausea, vomiting, and heartburn in pregnancy: a prospective look at risk, treatment, and outcome, Journal of Maternal-Fetal and Neonatal Medicine; 25 (8):1488-93.

6. Einarson. T., Piwko. C., \& Koren, G., (2013): Quantifying the global rates of nausea and vomiting of pregnancy: a meta-analysis. Journal of Population Therapeutics and Clinical Pharmacology, 20 (2), e171-e183.

7. Hyun Joung Choi, Yoon Joo Bae, June Seek Choi, Hun Kyong Ahn, Hyun Sook An, Dal Soo Hong, Jeong-Sup Yun \& Jung Yeol Han., (2018): Evaluation of nausea and vomiting in pregnancy using the Pregnancy-Unique 
Quantification of Emesis and Nausea scale in Korea, Journal of Obstetric and Gynecological Science;61 https://doi.org/10.5468/ogs.2018.61.1.30.

8. Hinkle S., Mumford S., Grantz K., Silver R., Mitchell E., Sjaarda L., Radin R., Perkins N., Galai N., \& Schisterman E., (2016): Association of Nausea and Vomiting during Pregnancy with Pregnancy Loss: a secondary analysis of a randomized clinical trial, JAMA Intern Med; 176:1621-7.

9. Koren G., Madjunkova S., \& Maltepe C., (2014): The protective effects of nausea and vomiting of pregnancy against adverse fetal outcome-a systematic review, ReprodToxicol; 47:77-80.

10. Lorzadeh N., \& Kazemirad S., (2013): The effects of fetal gender on serum human chorionic gonadotropin and testosterone in normotensive and preeclamptic pregnancies," Journal of Pregnancy, vol. 2013, Article ID 874290, 6 pages,Asali Hospital, Lorestan University of Medical Sciences, Lorestan, Iran.

11. Mojgan Naeimi Rad \& Minoor Lamyian., (2015): Quality of life in women with nausea and vomiting from pregnancy, Caspian Journal of Reproductive Medicine, 1(3): 18-21, Journal homepage: www.caspjrm.ir.

12. Marie Balíková \& Radka Bužgová (2014): Quality of women's life with nausea and vomiting during Pregnancy; 5(1):29-35 ISSN 1804-2740.

13. Naomi Mitsuda, Masamitsu Eitoku1, Nagamasa Maeda, Mikiya Fujieda, \& Narufumi Suganuma, (2019): Severity of Nausea and Vomiting in Singleton and Twin Pregnancies in Relation to Fetal Sex, The Japan Environment and Children's Study (JECS), Journal of Epidemiology;29 (9):340-346.

14. Nayak. S., \& Sunanda. B., (2017): Relationship between Morning Sickness during Pregnancy and Infant Gender among Postnatal Mothers. I-manager's Journal on Nursing, 7 (2), 21-26. https://doi.org/10.26634/jnur.7.2.13692.

15. National Institutes of Health, (2016): Melasma (Mask of Pregnancy), National Library of Medicine, Medline Plus Medical Encyclopedia, Melasma, October 2016.

16. Pregnancy, Birth \& Baby (2019): Changes to your skin during pregnancy, https://www.pregnancybirthbaby.org.au/changes -to-your-skin-during-pregnancy.

17. Pauliina Ellilä, P., Laitinena. L., Nurmia. M., Rautavab, P., Koivistoc. M., \& Päivi PoloKantolaa. P., (2018): Nausea and vomiting of pregnancy: A study with pregnancy-unique quantification of emesis questionnaire, European Journal of Obstetrics \& Gynecology and Reproductive Biology 230 (2018) 60-67.

18. Sarkar R., \& Bansal S., (2017): Skin pigmentation in relation to gender: truth and myth. , Panchsheel, New Delhi, India, Pigment Int; 4:1-2.

19. Sarah R., Crozier, Hazel M., Inskip, Keith M., Godfrey, Cyrus Cooper, Sian M. Robinson, SWS Study Group (2017): Nausea and vomiting in early pregnancy: Effects on food intake and diet quality, Maternal \& Child Nutrition. https://doi.org/10.1111/mcn.12389.

20. Veenendaal, M., Van Abeelen, R., Painter, J., Van Der Post \& Roseboom, (2011): Consequences of hyperemesis gravidarumforoffspring: a systematic review and meta-analysis BJOG, 118(11): 1302-13.

21. Vida Shafti \& Maryam Zakerihamidi (2017): Relationship between Nausea and Pregnancy Vomiting and Fetus Gender, J NeyshaburUniv Med Sci 2017, 5(1): 66-72

22. Zare F., \& Sekhavat L., (2013): Relationship Between Fetal Sex and Nausea and Vomiting During Pregnancy, ShahidSadoughi University, Yazd, Iran, World Applied Sciences Journal 23 (7): 935-937, ISSN 1818-4952. 